\title{
Manufacturing knowledge: Going from production of things to designing value in use
}

\author{
Åsa Ericson ${ }^{\mathrm{a}, *}$, Christian Johansson ${ }^{\mathrm{b}}$ and Henrik Nergård ${ }^{\mathrm{a}}$ \\ ${ }^{a}$ Product Innovation, Luleå University of Technology, Luleå, Sweden \\ ${ }^{\mathrm{b}}$ Department of Mechanical Engineering, Blekinge Institute of Technology, Karlskrona, Sweden
}

\begin{abstract}
A new vision in manufacturing is to develop product-service integrated value solutions. Today, few firms have fully realized this vision because they are not able to support the reasoning in the early stages of design. The purpose of this paper is to discuss engineers' cognitive challenge when replacing the core product rationale with value logic. The paper problematizes engineering design by dividing knowledge into the categories technically constructed (explicit) and socially constructed (tacit). In doing so, this study contributes the assumed effects of a perspective shift that could guide the development of computational tools.
\end{abstract}

Keywords: Product-service systems, knowledge management, value-driven design, conceptual design, knowledge maturity

\section{Introduction}

Modern business strategy is commonly said to have roots in a new knowledge-based society. Proof of such a concept can be seen in the ManuFuture report presented in 2004 [14], which states that the knowledge content of manufactured products should ideally reach the level of at least $20 \%$ of a product's content in 2020. Further, taking a historical view, the trend of increasing products' knowledge content can be seen beginning from the end of the Second World War (5\% in 1945 ) and moving into the 21 st century ( $16 \%$ in 2004). This implies a transformation of the fundamental processes of manufacturing. That is, knowledge is not only used to optimize specific production tasks, but knowledge is also captured and transferred - via platforms and competence networks - to other areas in which it can be advantageously employed [14].

However, what knowledge is in a knowledge-based society is not as straightforward as it seems in engineering literature. That is, not all knowledge is dis-

* Corresponding author: Åsa Ericson, Product Innovation, Luleå University of Technology, 97187 Luleå, Sweden. Tel.: +460920 49 20 61; E-mail: asaeri@ltu.se. crete and explicit, and not all knowledge can be readily turned into codified processes, as the literature assumes. For example, from a knowledge-based engineering perspective, the activities of identifying, justifying, capturing, formalizing, packaging, and activating knowledge are important [44]. These steps are needed in order to represent and store knowledge with the aim of reducing the time and cost of building knowledge platforms or applications, but they also indicate that the knowledge is readily accessible and exists in an explicit form. However, Bell [5] concluded that only $4 \%$ of organizational knowledge is formalized in a structured form, whereas $16 \%$ is stored as unstructured data, and as much as $80 \%$ is stored in people's minds. The challenge of not having procedures that formalize experiences and know-how is still apparent in the manufacturing industry. A firm's low level of formalized organizational knowledge might stem from a failure to apply satisfactory methods and from a narrow view of what actually constitutes knowledge.

Basically, management literature distinguishes between two main categories of knowledge: explicit and tacit (e.g. [21,36,37]). Explicit knowledge's characteristics make it fairly similar to, for example, facts and information - what is referred to as know-what. On the other hand, tacit knowledge is context dependent and 
relates to experiences, often referred to as know-howthat is, practical knowledge applied in a specific context [23]. Riding a bike is a commonly used example of know-how, or tacit knowledge: it is difficult to explain how to do it; one has to try it. The European Union's Lisbon Strategy [28] indicates that a knowledge-based economy drives economic growth, thus reflecting the imperative that companies broadly address knowledge in their product designs. That is, knowledge management should not only fulfil the goal of formalizing what firms actually know but should also meet the goal of creating a base for innovative product development and user orientation.

Trends such as innovative development, user orientation, and servicification have recently become evident in manufacturing industry. The trend of servicification, which is captured in the concept of productservice systems [34], describes a new situation in which a manufacturing firm's offers are based on value. The offer meets customer requirements when the total solution - that is, everything that can be provided by the supply chain - delivers the intended outcome in the customer's processes. Visions to bring value to customers' processes can today be seen in contemporary manufacturing companies', for example, lower the customer's cost by $30 \%$ or increase the customer's efficiency by $10 \%$. Such intentions in practical terms mean that engineers must design for customerperceived value rather than employing, as they usually do, an existing product specification as the guiding template. Simply put, manufacturing firms have expressed an interest in shifting from being productfocused to being service-oriented organizations, but they cannot foresee how to accomplish this. In order to contribute to the adaptation of computational knowledge-management tools for the early stages of product development, this paper discusses the engineer's cognitive challenge when replacing the core product rationale with value logic. Owing to a lack of real cases in which manufacturing firms have implemented the value logic, the paper concludes with the assumed effects of the perspective shift.

First, we present a short explanation for the methodology applied in this paper. Second, we detail the servicification and knowledge perspective of early stages of product development, and in parallel, also problematize and discuss them. The discussion derives from research conducted in collaboration with industry, but the paper is delimited in terms of accounting in detail for the generation and analysis of the empirical material.

\subsection{Methodology}

This paper is based on empirical data about companies' efforts so far to adapt activities and tools for servicification. The data was obtained through previous research activities but not exclusively outlined. The paper can thus be seen as conceptual, but the discussion is grounded in extensive data. The data, acquired through interviews, observations, and informal interactions with many manufacturing companies, is mainly qualitative and was collected between 2003 and 2012. Much of it was gathered through a large research project conducted in the aerospace industry that gave us access to over 59 partners [12].

The companies studied are medium and large in size and develop various products; a common characteristic is that they all act in a business-to-business environment. The underlying premise of the paper, the trend of servicification in the manufacturing industry, gets at the heart of these companies' business strategies. Demonstrators were developed in the research projects, and this approach has been applied so as to test and evaluate research ideas in the industrial setting. These activities provide, as outlined here, a source for the conceptual discussion from which we draw our conclusions.

\section{Servicification}

Service, from an engineering perspective, mainly addresses maintenance, repair, and overhaul - that is, services that keep goods operating. However, the idea of the servicification of a manufacturing firm includes not only training and education in operating the product [2] but also extending knowledge domains from a development logic based on products to designingin customer-perceived value and performance [29]. Frankly, instead of thinking of and designing goods, engineers must think and design "value." Yet value is a fuzzy, not to mention complex, concept whose definition depends on how and in what context it is used, as well as by whom. To avoid misunderstandings of translation, engineers must apply more-developed mental models of what constitutes the knowledge base in this unfamiliar situation, as well as helpful computational support. The early design stages are likely to become even more important than they already are not only for deciding upon product appearances but also in order to incorporate value assets that are important for the product's performance in customer processes. This can be seen as servicification's shift into mass production. 
Incorporating servicification as a holistic guiding principle for engineers has proved a challenging task for industry because servicification includes innovation opportunities, while contemporary models and tools handle mainly existing product-related knowledge. Through servicification's introduction, engineers' cognitive models must move beyond the traditional scale of the designing and manufacturing process, shifting from production of things to delivery of value. Overseeing and anticipating later parts of the whole process of design and production will become even more essential to the servicification design process, for engineers must incorporate and manage the extended product life cycle from understanding user behaviour to the fulfilment of users' perceptions of value.

As the concept of a product moves from a physical commodity towards becoming one of several value carriers, a need arises to equip engineers with computational tools that support them in understanding the business case, managing innovation opportunities, and executing sound decisions in the early stages of product development processes. A key issue for engineers is not exceeding the allocated development budget while simultaneously searching and choosing among several alternatives. This focus, called loss aversion (i.e., the fear of exceeding the predicted costs), can prevent engineers from choosing a solution that is probably better in a specific situation [16]. Therefore, a computational method based on fuzzy numbers has been suggested to decrease such biases in human decisionmaking processes [16]. Another key issue for engineers is the optimization of chosen solutions. However, models used for optimization are often idealized estimations of real-life problems, creating uncertainty regarding constraints [13]. Instead of exploring the potential of several alternatives, engineers tend to limit or partition the search space so as to reduce the computational running time. As demonstrated [13], such barriers are addressed by the framework of CogInfoCom and could support manufacturing firms in decision making for servicification.

Mintzberg and Westley [33] distinguished among "thinking first," "seeing first," and "doing first" styles of decision making. Thinking first is appropriate when one, for example, can apply control to the input/output and when the problem occurs in a structured context. Seeing first is typically helpful in new product development, in which both creative solutions and crossboundary communication are vital. Doing first is suitable in situations that are novel or confusing and when

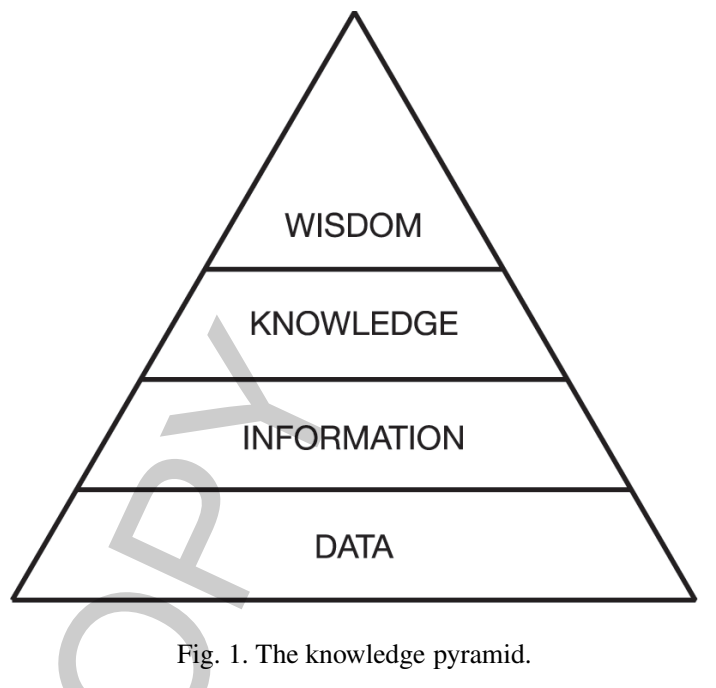

decisions are hampered by complicated specifications. Owing to an increased degree of uncertainty, decision support for servicification solutions seems to require that engineers (virtually) see and do beforehand in order to facilitate a new type of knowledge management.

\section{Knowledge and the product development process}

Any effort to define the term knowledge in an absolute way can be considered vain, a task that the ancient Greeks began and that researchers in modern society are still debating. In particular, perspectives diverge into technological and human science views. Therefore, knowledge research can be controversial; knowledge is important to most firms, however, and the management of knowledge is of utmost concern for product development. Those firms that find knowledge management truly essential thus also need to find a practical definition of knowledge. Given that manufacturing firms are often organized in a product-oriented fashion, they commonly define knowledge as, for instance, facts and methods - that is, as known quantities.

From a knowledge perspective, the product design process comprises activities that build a body of information and knowledge into a complete formula for the production and the launch of a product [42]. Hence, the idea of engineering as knowledge intensive work is firmly established in the research.

In knowledge- and information-management literature (e.g. [17,20,39]), the distinction among data, information, and knowledge is often made and has been illustrated in the knowledge pyramid (Fig. 1), also 
known as the DIKW hierarchy. It should be stressed that the top of the pyramid, wisdom, is a controversial matter, since the transition from knowledge to wisdom is vague. In addition, use of a pyramid indicates that the higher aspects are sought after and more valuable, though this is not always the case [43]. On the contrary, one's preexisting knowledge influences which data one collects and how one measures or assesses it [46], so there is also a feedback down the pyramid [24]. For instance, in the design of technologies and systems (often governed by the Technology Readiness Levels; TRLs [30]), the difference between knowledge and a pure guess is often the evidence that is either measured or observed - that is, the data or the information [31]. Something is not "known" unless one can prove it to be right.

Forming the bottom of the pyramid (Fig. 1), data is considered raw material consisting of figures, letters, numbers, or similar items in no particular order. Data comes directly from an instrument without any processing (it should be noted that a person can be the instrument). A coding key, which stipulates how to read, combine, or transform the data, is needed to achieve information. A context - for instance, a design vision or a problematic situation - is needed to accomplish the transformation from information to knowledge [39]. Typically, it is concluded that knowledge is contextually dependent [37]. Consequently, what one person considers knowledge may to another be simply information or even data. On a similar note, Wickler and Potter [49] has highlighted this issue - in the context of fire prevention - also from an information-processing perspective. The 'information-gathering' problem [49] needs to be address through three phases - data validation, data aggregation and abstraction, and information interpretation - to ensure that the information is accurate, concise, timely, and meaningful. Finally, the pyramid metaphor implies that the lower steps require larger quantities that transform into the more compact, higher levels [20].

The core logic in product development models [47] indicates that the range of information/knowledge searched for should converge as quickly as possible. Practically, this means that an early decision to precisely set the product specifications is beneficial in terms of, say, decreasing time to market but is also negative because it becomes a barrier to building knowledge platforms for future products. That is, limited data and information are explored in order to gain information about future markets, customers, and new extended solutions. In straightforward terms, the knowl- edge base becomes too focused and too limited for the new business of servicification. As an example, a company may focus only on producing a product or goods to satisify an end market instead of looking within to see which elements of its internal processes or knowhow could be sold to other companies (or other stakeholders within the company) so as to innovate or increase the servicification of the business.

\subsection{Managing knowledge}

Research literature describes a first and a second wave of knowledge management [1]; both are needed to execute the design and development of servicification. The two exhibit clear differences, however (see Table 1), not only in the ways they are applied but also in their aims and reasoning. The first wave is described as focusing on controlling and monitoring organizational knowledge flows. Representative questions that guide the efforts are the following: How can we identify our knowledge assets? How can we capture and formalize our knowledge? How can we disseminate and reuse the knowledge? From the perspective of the first wave, knowledge is tangible; it can be transferred from one instance to another. Knowledge "carriers" are typically facts, measures, validated and formal procedures, and so on. Typically, this is what can be related to the idea of explicit knowledge, or information, as defined by Nonaka et al. [37]. Information has been described by some researchers as a "flow of messages" (e.g. [17]), and in light of the knowledge pyramid it can be argued that just because one is informed does not necessarily mean that one possesses the knowledge to take appropriate action. That is, the receiver might lack the necessary understanding of the context (i.e., a coding key) and hence be unable to transform the information into knowledge.

The second wave of knowledge management is described by Ackerman et al. [1] as intended to empower people by providing them opportunities to learn anew. Here, a characteristic of knowledge is that it is subjective and socially constructed, emerging when people solve a problem jointly and reflect on the work performed. From this perspective, knowledge is highly individual and contextually dependent. People learn individually but also collectively via the reflection that takes place within teams. Team actors can recall previous situations, comparing them with new ones and considering any similarities when facing a new and problematic situation [41]. They develop not only experiences but also a joint coding key from which the learning curve can become steeper in similar future projects. 
Table 1

Differneces in Approaches (adapted from [22])

\begin{tabular}{lll}
\hline & 1st wave approach & 2nd wave approach \\
\hline Why is knowledge shared? & Managerial purposes & Daily work \\
When is knowledge shared? & When there is an opportunity to do so & When there is a need to do so \\
Where is knowledge shared? & On an operational level & Organizationwide \\
Whose knowledge is managed? & Individual: human capital & Collective: social capital \\
What knowledge is shared? & Codified & Tacit and codified \\
How is knowledge shared? & Via repository systems and electronic networks & Via personal and electronic networks \\
\hline
\end{tabular}

Servicification, with its increased service content and increased interest in designing customer-perceived value, is in the manufacturing industry considered a novel context in which engineers generally lack previous experience in making sense of the intangible and quite subjective knowledge about what customers perceive as valuable. Therefore, one important imperative in manufacturing is to develop methods of managing the type of knowledge defined by the second wave of knowledge management.

In general, first-wave knowledge-management support is well established in the manufacturing industry, at least in medium- to large-size companies. Applications like Product Data Management (PDM) and Product Lifecycle Management (PLM) systems are examples of such useful tools. Data mining and knowledge discovery in databases (KDD), which are means of capturing and making manufacturing knowledge available for reuse, have also gained a fair amount of attention over time (e.g., [3]). Many first-wave knowledge management systems can be categorized as expert/knowledge systems because they allow management to keep track of the knowledge and provide the option for them to keep up to speed on the status. Usually, these systems are built upon knowledge rules that must be upgraded and refined by a system manager as new knowledge emerges. Owing to, for example, a lack of compatibility between different companies and the resources needed to maintain such knowledgemanagement systems; these systems can be described as "heavyweight" [8]. Captured knowledge is formalized into codified procedures (i.e., made explicit and contextualized) and is thus considered an essential organizational resource.

The second wave of knowledge management needs applications and systems that provide a platform for knowledge and experience build-up - in other words, expertise sharing. Such support is based on users' activities and interactions; thus, users themselves build up the content and keep it updated. To distinguish these from the traditionally used applications, they can be categorized as lightweight [8]. Lightweight tools do not, for example, require a particular infrastructure (except Internet access) to connect companies and, as mentioned, those who use them continuously maintain them.

In the case of the servicification business model, manufacturing companies have stated that they need to collaborate more closely with customers, suppliers, and additional firms in, for instance, the insurance, banking, and servicing industries. Collaboration across organizational borders offers the prospect of both developing value-adding products and successfully providing long-term offers. In light of the challenges servicification presents, giving rise to many uncertainties and risks, companies find it necessary to collaborate and to share knowledge, risks, and resources. This means that it is also necessary for them to develop and apply appropriate approaches so as to enable closer teamwork in early design.

The issues of security and the protection of knowledge from leakage are often mentioned as reasons not to invest in lightweight types of support [7], while it can be argued that different organizational contexts constitute a "natural" way to safeguard the knowledge (i.e., knowledge is transformed using different coding keys). If so, sharing tacit knowledge within a collaboration or partnership would be a win-win situation.

\subsection{An extended knowledge life cycle}

As argued above, in order for knowledge to be transferable to another recipient, whether an individual or a group, it needs to be codified; subsequently, in order for that knowledge to become useful, the recipient must have access to a coding key (e.g., insights into the context or knowledge based on a similar situation). Tacit knowledge, which is usually produced in practice, is difficult to identify and capture, thus intentional and direct activities to codify it are generally lacking. However, this lack does not relate simply to the tacit dimension; lack of motivation also stems from economic concerns. The codification activities of knowledge do not show an immediate return on the investment [11], and for some firms this raises serious concerns about 
whether such activities are too costly. How firms allocate resources for knowledge-management activities and the kind of knowledge that is addressed may at first seem to depend only on organizational and cultural aspects, but the questions also, it can be argued, arise from the lack of a diversified view of knowledge. Concrete, physical, and discrete are common key words that describe technical product-related knowledge, while immaterial, subjective, and social describe the perspective of an extended knowledge base for servicification. Likewise, there are two main types of tacit knowledge: uncodifiable (i.e., truly tacit) and not yet codified [11].

The descriptions of different knowledge life cycles highlight that knowledge-management efforts are likely to differ depending on the predefined and followed steps. For example, McElroy [32] suggested the stages production, integration, and diffusion/application, which convey a knowledge management process based on already codified procedures - that is, on the management of known characteristics. Blessing and Wallace [9] proposed the stages outside sources, generate, capture, learn, store, retrieve, and use. Their proposal stresses not only the search for additional knowledge (e.g., outside the team, the department or the company) but also a learning process whereby new knowledge is created. These stages convey a knowledgemanagement process based on the exploration of unknown characteristics.

\subsection{Knowledge-maturity scales}

As the knowledge base becomes wider, it also becomes more ambiguous, and uncertainty increases. Commonly, engineers (as most people do) approach an unfamiliar situation by asking the question "Have we done this before?" That is, they begin by searching for some frame of reference within which to interpret the new situation. But applying a method to filter out all uncertainty (a risk perspective) diminishes the basis for finding product-service solutions. Therefore, exploring the new situation (an opportunity perspective) is preferable. For this reason, engineers must be comfortable preserving ambiguity throughout the exploration stages. This is not to say that manufacturing firms should always decide to implement radical solutions; rather, they should learn from the modelling and simulation of additional knowledge perspectives.

In order for engineers to move beyond applying a "business-as-usual" method in early design - thinking only about how to solve the technical development problem - they need support to communicate their cognitive model, the kind of information and knowledge that their decisions are based on. Commonly, an approach that relies on measurements and facts leads people to believe that a subjectively set measure is more objective and "real" than it actually is. Representatives of manufacturing companies have said that if someone prescribes a measure, however subjective it is, it becomes not only a fact but also a problem over time. Product development - in particular, productservice, or servicification - deals daily with subjective assessments. However, those are commonly not made explicit because a method (even a simple one) for visualizing this generally does not exist.

Apart from subjective assessments, it is also common for engineers to apply placeholder values [15], that is, educated guesses - that can be used in place of the true values to keep development moving forward. Nevertheless, these cannot be perceived as representing the truth; such guesses should, at some stage of the development work, be exchanged for "real" knowledge that has been proved true. In real life, however, this is not always easy, given that development can advance quite far and many decisions need to be made before these placeholders are corrected. In some cases, they have even been "forgotten" and accepted as valid well into the development process. What is needed is a way of representing and assessing the level of certainty, indicating to what extent information can be trusted.

Maturity can be understood as "a compromise between the target uncertainty and the expected uncertainty" [18, p. 282], meaning the difference between the level of uncertainty (and information and knowledge) at which one can be certain and the current state of uncertainty. This could be seen either as a percentage or as a certain step on a ladder. Bohn has defined maturity of knowledge as "understanding the effects of the input variables on the output" [10, p. 63], meaning that whatever one feeds into an activity will in some way affect the end result. A high level of knowledge maturity allows one to predict the result based on what one does and on the information one uses in the activity. The notion of knowledge maturity has been further developed into a decision support [25]. In this view, understanding cannot be separated from the working context or, for that matter, from the people doing the work. Hence, knowledge maturity, as Johansson developed it [25], uses input information, tools, and methods, as well as people's experience and expertise, to represent the current state of certainty.

Often, the reasoning behind how certain activities are performed or which activities are performed, and 
Table 2

Narrative knowledge-maturity scale (adapted from [26])

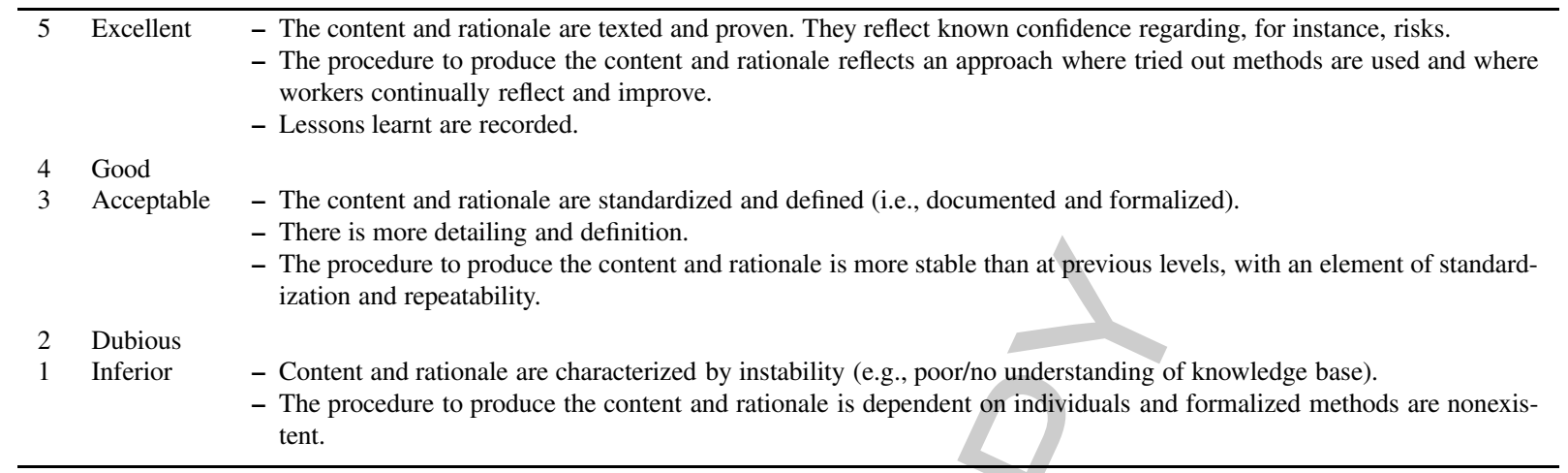

why, hinges on the rationale that these are "things we just do." In other words, these decisions are based on organizational culture, routines, and praxis. Such choices depend on varying contexts, even in specific departments, on people's preferences, or on specific organizational capabilities in certain methods or domains. Knowledge-maturity scales represent an effort to inspire debate and dialogue in order to make the reasoning visible. That, in turn, can provide an improved foundation for decisions.

Like the Technology Readiness Levels (TRLs) developed by NASA to guide technology and system maturation through development [30], knowledge maturity scales [26] feature narrative definitions of knowledge-base levels. The TRLs scale features 9 steps, whereas the knowledge-maturity scale features five steps, ranging from "inferior" to "excellent" knowledge (see Table 2).

As previously mentioned, knowledge-maturity scales have been developed to cover input, methods, and experience (see Table 3 ) and to more comprehensively represent the understanding of the current certainty level. The aim is to make the notion of knowledge maturity less abstract for assessment purposes. The input dimension relates to information coming into the project from the outside, information that can have varying degrees of dependability. The method dimension deals with a wider view on tools, procedures, and methods, allowing decision makers to assess the dependability of these based on validation and verification, as well as according to their suitability for a given purpose. The experience dimension surveys the "human factor" within a development project. Those who do the work have different degrees of expertise, sometimes within very specific fields of application, whereas it is also inevitable that management will need to staff projects with people who are novices to some degree, given the ongoing rotation of personnel.
Knowledge maturity is intended as a complement to the development of the core product and service aspects, which are often assessed using the TRLs scale. Each development project requires some learning about the product or service in order to reduce uncertainty. This "knowledge journey" is followed up on using the knowledge-maturity scales.

In the case of servicification, in which knowledge especially about customer-perceived value - can be quite subjective and riddled with uncertainty and ambiguity, it is essential to visually communicate the assessed maturity. Thus, there is a need to support the empowerment of engineers by also addressing the second wave of knowledge management.

\section{CogInfoCom and servicification}

The established supports and procedures that have successfully managed the first wave of knowledge, it could be argued, have become the grand challenge for implementing complementary qualitative and subjective approaches. The successful implementation of servicification in a manufacturing company will have an effect on all levels, particularly on the design and use of computational support. Company representatives have recognized and discussed that the established knowledge management approaches do not provide sufficient support for widening the knowledge base; for instance, they do not support the search for innovative solutions and do not capture the experiences of elaborating on and assessing alternative solutions. Any shift in perspective faces a period of debate and gatekeeping [27], which delays and hinders progress. There is also a tendency to view the shift from an "either/or" point of view. This is especially a barrier in servicification, which addresses the domains of service and prod- 
Table 3

Knowledge-maturity scale for input, method and experience (adapted from [26])

\begin{tabular}{|c|c|c|c|c|}
\hline & & Input & Method & Experience \\
\hline 5 & Excellent & Input is detailed and verified. & $\begin{array}{l}\text { Tested, standardized, and verified } \\
\text { methods that are under continuous re- } \\
\text { view and development. }\end{array}$ & $\begin{array}{l}\text { Long verified experience and expertise } \\
\text { within area of concern. }\end{array}$ \\
\hline 4 & Good & & & \\
\hline 3 & Acceptable & $\begin{array}{l}\text { Input is available in detailed form but } \\
\text { is not verified. }\end{array}$ & $\begin{array}{l}\text { Standardized and texted methods have } \\
\text { been used. }\end{array}$ & $\begin{array}{l}\text { Proven experience and competence } \\
\text { within area of concern. }\end{array}$ \\
\hline 2 & Dubious & & & \\
\hline 1 & Inferior & Risk of incorrect input data. & $\begin{array}{l}\text { Untried methods have been used (ad } \\
\text { hoc). }\end{array}$ & $\begin{array}{l}\text { The person doing the work is inexpe- } \\
\text { rienced (first time). }\end{array}$ \\
\hline
\end{tabular}

uct thinking. A service-management perspective advocates that firms abandon the product perspective if they intend to turn to servicification. The proponents of service management suggest that the mental model of the product as the main value carrier should be replaced by, for example, resources such as personnel, technology, knowledge, and time, and that the manufacturing firm should be able to address all stakeholders' needs, wants, desires, and expectations [19]. Yet Normann (2001) [38] argued that companies seldom abandon old models because they are not completely irrelevant. And in the case of servicification, the product is certainly still vital, but the complexity increases owing to the necessity of addressing several business models. These models are the following (adapted from [45]):

- Product oriented: the ownership of the product is transferred and additional services are provided, as in transactions involving stand-alone products (i.e., a conventional manufacturing business model).

- Use oriented: no ownership is transferred, but the firm allows customers to use the product themselves as a service (e.g., leasing or renting).

- Result oriented: no ownership is transferred; rather, customers pay when they benefit from the product's performance (the scissors) when it is used by someone else, as in services (e.g., a haircut).

The last category is not only the optimal servicification but also a grand intellectual challenge for manufacturing firms on several levels of abstraction. For example, new value-chain models are needed, as are approaches for incorporating the customer as a contributor in the planning stages.

Rather than focusing on later stages - for example, how to sell and whether the customer owns the product - a resource-based knowledge model could usefully sustain a shift from product to value. From a resource-based perspective, a transition from one reasoning to the other is described in the visualization of a conceptual vocabulary for goods-dominant concepts (G-D) and service-dominant concepts (S-D) [29, p. 286], as outlined in Table 4.

Again, a transition from one strand to another has been suggested in service literature because researchers have concluded that that the rationales for product development and service development involve two entirely different styles of reasoning, and whether those can be managed simultaneously has been questioned [48]. The gatekeeping of contemporary approaches is dominant in the manufacturing industry. CogInfoCom, which has emerged from a synergic combination of cognitive science and infocommunications [40], could provide a feasible way to break down the barriers between product development and service development. The convergence of sciences brings additional advantages, and the impact of such synergy could give rise to new approaches, platforms, products, services, and applications [40] - all in all, to what is also expected from the product-to-value shift in industry.

Further, the development of computational support for engineers relies generally on traditional technical reasoning. This implies that these tools often lack a feature to directly capture or support innovative reasoning; instead, they depend on factual knowledge (e.g., historical data) and a support developer who updates and maintains that knowledge. Some companies have implemented specially designed rooms equipped with virtual reality tools. Despite the high expectations on such new technology as an aid in work, engineers do not commonly use them. Engineers have, though, expressed the importance of interacting with a physical product (feel, touch). This might, on one hand, explain why engineers have trouble incorporating the intangible aspects of servicification into their reasoning. On the other hand, it would, if considered in the design of computational support, facilitate servicification if the aim were to make intangibles visual. One such example is a colour-coded CAD tool that 
Table 4

Conceptual vocabulary (adapted from [29])

\begin{tabular}{lll}
\hline G-D logic concepts & Transitional concepts & S-D logic concepts \\
\hline Products & Offerings & Experiences \\
Feature/attribute & Benefit & Solution \\
Value added & Co-production & Co-creation of value \\
Profit maximization & Financial engineering & Financial feedback/learning \\
Price & Value delivery & Value proposition \\
Equilibrium systems & Dynamic systems & Complex adaptive systems \\
Supply chain & Value chain & Value-creation network \\
Product orientation & Market orientation & Service orientation \\
\hline
\end{tabular}

demonstrably supports decision making by increasing engineers' awareness of value in relation to servicification (e.g. [6]). The use of colour makes it possible not only to consider the tangible and intangible value of each design alternative but also to estimate knowledge maturity. This approach proposes that engineers need to understand how a concept is positioned against a benchmark (e.g., the actual product performances, which determine a baseline) and a target (e.g., a specific long-term forecast, which makes it possible to compare different value dimensions) [6]. The result can subsequently be assessed in relation to different business models and classified as product oriented, use oriented, or result oriented. Understanding and assessment are in this case practicable, even though absolute value scores are not achievable owing to the intangible elements of servicification [35]. The colour-coded approach has gained interest among companies developing 3D CAD support; the tool will basically become a complement to existing solutions. Hence, there remains a need to address ways to capture, formalize, and represent the socially constructed knowledge that engineers build when interpreting the result from the screen - that is, to address the infocommunication between the application and the human beings. CogInfoCom provides one such wider view on support because it not only incorporates stored information but also emphasizes users' interaction with it [4].

\section{Concluding remarks}

Many manufacturing firms have adopted a vision of increasing the knowledge content and thus the service content of their solutions. Yet they remain in an early stage of business execution, and there are few examples of optimal servicification, or of result-oriented business solutions [45]. Even fewer are the examples of best practices within the manufacturing industry for managing and supporting a wider knowledge base in early product development activities.
This paper touches upon a need to rethink the design of engineering computational support in light of the industry's changing focus, which has shifted from product production to value provision. We have outlined an in-depth view of the distinct nature of explicit and tacit knowledge, as well as two different strands of knowledge management, in order to problematize engineering design for servicification. In order to explore the subject, we framed the discussion according to an either/or perspective. However, although real product design manages the complexity of blurred relations between explicit knowledge (e.g., information) and tacit knowledge (e.g., experiences), it is an acknowledged fact that manufacturing companies lack support for and insight into those situations. As it stands, the development of engineering design support rests upon a technical tradition, thereby manifesting an unwillingness to change mental models and sustaining business as usual. We have highlighted that CogInfoCom, because it addresses both infocommunication devices and cognitive science, could provide insights into the stepwise learning process that the manufacturing industry needs to implement in order to shift from product development to value provision.

\section{Conclusions}

Because this paper puts forward a conceptual approach, discussing and problematizing the issue, conclusions cannot be drawn in a general manner. In the case of servicification, as presented here, it can be assumed that a traditional knowledge-management approach is not sufficient. We propose that the inclusion of innovation and user orientation in servicification is one reason for this and that the issue of managing intangibles is another. The argumentation is that experiences (e.g., know-how), which constitute a wider knowledge base, develop when engineers interact with the servicification task but are not supported by appropriate tools for engineering design. Including CogIn- 
foCom science could provide a trigger for addressing the interaction between engineers and their tools as a serious attempt to ease the implementation of servicification in early product development.

\section{Acknowledgments}

We would like to acknowledge VINNOVA for financing this work via the Innovative Product Development Programme (Innovativ produktframtagning). The collaboration in INTERREG IVA North Project SMaE Sustainable Manufacturing and Engineering is also acknowledged. Finally, we thank participating company representatives, who contributed invaluable discussions to this work.

\section{References}

[1] M. Ackerman, V. Pipek and V. Wulf, eds, Sharing Expertise: Beyond Knowledge Management, Cambridge: MIT Press, 2003.

[2] T. Alonso-Rasgado, G. Thompson and B.-O. Elfström, The design of functional (total care) products, Journal of Engineering Design 15(6) (2004), 514-54.

[3] B.A. Badiru, Expert Systems Applications in Reconfigurable manufacturing systems: Key to future manufacturing, Eaglewood Cliffs: Prentice Hall, 1992.

[4] P. Baranyi and A. Csapo, Definition and Synergies of Cognitive Infocommunications, Acta Polytechnica Hungarica 9 (2012), 67-83.

[5] S. Bell, Lean enterprise systems: Using IT for continuous improvement, Hoboken: John Wiley \& Sons, 2006.

[6] A. Bertoni, Value assessment capabilities in early PSS development: A study in the aerospace industry, Licentiate thesis, Luleå University of Technology, Sweden, 2012.

[7] M. Bertoni, K. Chirumalla and C. Johansson, Social technologies for cross-functional product development: SWOT analysis and implications, Proc. 45th Hawaii International Conference on System Science, Grand Wailea, HI: HICSS-45, 2012.

[8] M. Bertoni, A. Larsson, A. Ericson, K. Chirumalla, T. Larsson, O. Isaksson and D. Randall, The rise of social product development, International Journal of Networking and Virtual Organisations 11(2) (2012), 188-207.

[9] L.T.M. Blessing and K.M. Wallace, Supporting the Knowledge Life-Cycle, in: Knowledge Intensive CAD, S. Finger, T. Tomiyama and M. Mäntylä, eds., Dordrecht: Kluwer Academic Publishers, 1999, pp. 21-38.

[10] R.E. Bohn, Measuring and man- aging technological knowledge, Sloan Management Review 35(3) (1994), 61-73.

[11] R. Cowan, P.A. David and D. Foray, The explicit economics of knowledge codification and tacitness, Industrial and Corporate Change 9(2) (2000), 211-253.

[12] CRESCENDO Project, Retrieved April 19 2013, from: http:// www.crescendo-fp7.eu, 2012.

[13] Z. Danyadi, P. Foldesi and L.T. Koczy, Fuzzy Search Space for Correction of Cognitive Biases in Constructing Mathematical Models, Proc. IEEE 3rd International Conference on
Cognitive Infocommunications, Kosice, Slovakia: CogInfoCom, 2012.

[14] EU-Commission, Manufuture, Manufuture High Level Group Report, 2004.

[15] T. Flanagan, C. Eckert and P. Clarkson, Externalizing tacit overview knowledge: A model-based approach to supporting design teams, Artificial Intelligence for Engineering Design, Analysis and Manufacturing 21 (2007), 227-142.

[16] P. Foldesi and J. Botzheim, Computational method for corrective mechanism of cognitive decision-making biases, Proc. IEEE 3rd International Conference on Cognitive Infocommunications, Kosice, Slovakia: CogInfoCom, 2012.

[17] M. Fricke, The knowledge pyramid: A critique of the DIKW hierarchy, Journal of Information Science 35(2) (2009), 131142.

[18] K. Grebici, Y.M. Goh, S. Zhao, E. Blanco and C. McMahon, Information maturity approach for the handling of uncertainty within a collaborative design team, 11th International Conference on Computer Supported Cooperative Work in Design, Melbourne: CSCW, 2007.

[19] C. Grönroos, Service management and marketing: A customer relationship management approach, Chichester: Wiley, 2000.

[20] J. Hey, The Data, Information, Knowledge, Wisdom Chain: The Metaphorical link, Intergovernmental Oceanographic Commission, 2004

[21] J. Holste and D. Fields, Trust and tacit knowledge sharing and use, Journal of Knowledge Management 14(1) (2010), 128140.

[22] M.H. Huysman and D. de Wit, Knowledge Sharing in Practice, Dordrecht: Kluwer Academics Publishers, 2002.

[23] M. Ipe, Knowledge Sharing in Organizations: A Conceptual Framework, Human Resource Development Review 2(4) (2003), 337-359.

[24] M.E. Jennex, Re-visiting the Knowledge Pyramid, Proc. 42nd Hawaii International Conference on System Sciences, Waikoloa, HI: HICSS-42, 2009.

[25] C. Johansson, Knowledge Maturity as Decision Support in Stage-Gate Product Development: A case from the Aerospace Industry, Ph.D. Dissertation, Luleå University of Technology, 2009.

[26] C. Johansson, B. Hicks, A. Larsson and M. Bertoni, Knowledge Maturity as a Means to Support Decision Making During Product-Service Systems Development Projects in the Aerospace Sector, Project Management Journal 42(2) (2011), 32-50.

[27] T.S. Kuhn, The Structure of Scientific Revolutions (3rd edition), Chicago: University of Chicago Press, 1996.

[28] Lisbon Strategy, Retrieved April 20 2013, from: http://www. consilium.europa.eu/uedocs/cms_data/docs/pressdata/en/ec/ 00100-r1.en0.htm, 2000.

[29] R.F. Lusch and S.L. Vargo, Service-dominant logic: reactions, reflections and refinements, Marketing Theory 6(3) (2006), 281-288.

[30] J. Mankins, Technology Readiness Levels, NASA White Paper, 1995.

[31] J.C. Mankins, Technology readiness assessments: A retrospective, Acta Astronautica 65(9-10) (2009), 1216-1223.

[32] M. McElroy, The new knowledge management, Knowledge and Innovation: Journal of the KMCI 1(1) (2000), 43-67.

[33] H. Mintzberg and F. Westley, Decision making: it's not what you think, MIT Sloan Management Review (Spring 2001), 8993.

[34] O. Mont, Clarifying the concept of product-service system, Journal of Cleaner Production 10(3) (2002), 237-245. 
[35] H. Nergård and Å. Ericson, Changes in present product design: opportunities for industrial oriented research, Proc. IEEE 3rd International Conference on Cognitive Infocommunications, Kosice, Slovakia: CogInfoCom, 2012.

[36] I. Nonaka, The knowledge-creating company, Harvard Business Review (Nov-Dec 1991), 96-104.

[37] I. Nonaka, R. Toyama and N. Konno, SECI, Ba and Leadership: A Unified Model of Dynamic Knowledge Creation, Long Range Planning 33(1) (2000), 5-34.

[38] R. Normann, Reframing business: When the map changes the landscape, Chichester: Wiley, 2001.

[39] J. Rowley, The wisdom hierarchy: representations of the DIKW hierarchy, Journal of Information Science 33(2) (2007), 163-180.

[40] G. Sallai, The Cradle of Cognitive Infocommunications, Acta Polytechnica Hungarica 9(1) (2012), 171-181.

[41] D.A. Schön, The reflective practitioner: How professionals think in action, Aldershot: Arena, 1995.

[42] P.G. Smith and D.G. Reinertsen, Developing Products in Half the Time, New York: Van Nostrand Reinhold Book, 1991.

[43] D. Stenmark, The Relationship between Information and Knowledge, 24th Information Systems Research Conference in Scandinavia, Ulvik, Norway, 2001

[44] M. Stokes, ed., Managing Engineering Knowledge: MOKA Methodology for Knowledge Based Engineering Applications, London: Professional Engineering Publishing Limited, 2001.

[45] A. Tukker, C. Van den Berg and U. Tischner, Productservices: A specific value proposition, in: New Business for Old Europe: Product-Service Development, Competitiveness and Sustainability, A. Tukker and U. Tischner, eds, Greenleaf Publishing, 1995, pp. 22-34.

[46] I. Tuomi, Data is More than Knowledge: Implications of the Reversed Knowledge Hierarchy for Knowledge Management and Organizational Memory, Journal of Management Information Systems 16(3) (1999), 107-121.

[47] K.T. Ulrich and S.D. Eppinger, Product Design and Development (5th edition), New York: McGraw-Hill/Irwin, 2011.

[48] S.L. Vargo and R.F. Lusch, Evolving to a New Dominant Logic for Marketing, Journal of Marketing 68 (2004), 1-17.

[49] G. Wickler and S. Potter, Information-gathering: From sensor data to decision support in three simple steps, Intelligent Decision Technologies 3 (2009), 3-17. 